American Journal of Agricultural and Biological Sciences 5 (3): 301-308, 2010

ISSN 1557-4989

(C) 2010 Science Publications

\title{
Bioconversion Efficiency of $\beta$-Carotene from Mango Fruit and Carrots in Vitamin A
}

\author{
${ }^{1,2}$ Jose de Jesus Ornelas-Paz, ${ }^{1}$ Elhadi M. Yahia and ${ }^{3}$ Alfonso A. Gardea-Bejar \\ ${ }^{1}$ Faculty of Natural Sciences, Autonomous University of Queretaro, \\ Avenue of Sciences, 76230, Juriquilla, Queretaro, Mexico \\ ${ }^{2}$ Coordination of Physiology and Technology of Foods from the Temperate Zone, \\ Research Center for Food Research and Development, AC., \\ Rio Conchos Ave., Industrial Park, 31570, Cuauhtemoc, Chihuahua, Mexico \\ ${ }^{3}$ Coordination of Quality Assurance and Sustainable Use of Natural Resources, \\ Research Center for Food Research and Development, AC., \\ Km 6.6 of the Road to Varadero National, 85480, Guaymas, Sonora, Mexico
}

\begin{abstract}
Problem statement: Bioconversion efficiency of $\beta$-Carotene (BC) in vitamin A is strongly influenced by food matrix. This efficiency has been determined mainly in typical BC sources like carrots. $\mathrm{BC}$ content in mango fruit is considerably high however; the bioconversion efficiency of $\mathrm{BC}$ from fresh mango in vitamin $\mathrm{A}$ has not been determined nor compared with those of typical BC sources. Approach: Vitamin A depleted rats were daily fed with portions of Ataulfo mango (alone or with soybean oil), carrots and $\mathrm{BC}$ dissolved in soybean oil, during a two weeks repletion period. These food portions provided an identical daily dose of $\mathrm{BC}$ (122.1-132.1 $\mu \mathrm{g}$ ), which was considered as low. After repletion, the retinol accumulation in rat livers was determined. Results: BC was the major carotenoid in tested carrots and mangoes. BC content in these foods varied from 87.8 to 164.4 and from 17.4 to $1.2 \mathrm{mg} \mathrm{Kg}^{-1}$, respectively. Mango portions size delivered to the rats were higher than those of carrots but both provided the same amount of BC. Test foods portions were completely consumed by rats. Total intake of $\mathrm{BC}$ during the repletion period was identical in all experimental groups $(1.8 \mathrm{mg}$ ) however, the accumulation of retinol in rat livers varied among experimental groups. The highest retinol accumulation was found in rats feeding the oily solution of $\mathrm{BC}$. Co-consumption of mango and oil increase slightly the accumulation of retinol in rat livers, but statistical differences were not found. Rats fed with carrots accumulated 37\% less retinol than those feeding mango without oil. Conclusion/Recommendations: Ataulfo mango was more effective than carrots in improving vitamin A status in deficient rats. Delivered BC doses were efficiently absorbed, converted to vitamin A and stored as retinol. Further studies are needed to test the potential of mango in improving the vitamin A status in humans routinely ingesting the fruit.
\end{abstract}

Key words: Carotenoids absorption, bioefficacy, retinoids, healthy foods

\section{INTRODUCTION}

Vitamin A deficiency in children remains as an important public health problem in México and other Latin-American countries (Rivera and Supulveda, 2003). Vitamin A regulates the expression of several genes, tissue differentiation and exerts protective effects against some forms of cancer at the stages of initiation, promotion and progression (Bertram and Vine, 2005; Sampaio et al., 2007). This vitamin also is involved in human growth, reproduction, vision and eye health, immune function, lung function and general health of humans (Van Lieshout et al., 2001; Yahia and Ornelas-Paz, 2010). The major sources of vitamin A in the human diet are retinyl esters (preformed vitamin A) found in foods of animal origin and provitamin A carotenoids from fruits and vegetables. Unfortunately, foods containing preformed vitamin A are frequently too expensive for the economically deprived developing countries and therefore these people often do not receive sufficient amounts of the vitamin in their diets. Dietary carotenoids are the main source of vitamin A in these countries however, of the 600 different carotenoids that have been identified in natural sources;

Corresponding Author: Elhadi M. Yahia, Faculty of Natural Sciences, Autonomous University of Queretaro, Avenue of Sciences, 76230, Juriquilla, Queretaro, Mexico Tel/Fax: +52-442-228-1416 
only about 50 have provitamin A activity, being alltrans- $\beta$-Carotene $(\mathrm{BC})$ the main carotenoid precursor of this vitamin (Yahia and Ornelas-Paz, 2010). After cell uptake, $\mathrm{BC}$ and other provitamin $\mathrm{A}$ carotenoids are readily bioconverted to vitamin $\mathrm{A}$ esters by intestinal cells and transported to the liver where they are preferentially stored (Faulks and Southon, 2005). Thus, vitamin A accumulation in the livers from experimental animals has been used to determining the relative vitamin A value and provitamin A carotenoids bioavailability from foods (Tanumihardjo, 2002). Efficiencies of bioconversion of $\mathrm{BC}$ in vitamin $\mathrm{A}$ widely vary (35-100\%) as a consequence of many factors, including the BC absorption efficiency (Yahia and Ornelas-Paz, 2010; Van Vliet et al., 1995). Carotenoids absorption process is complex, requiring the carotenoids transfer from the food matrix to mixed micelles for delivery to the small intestinal epithelial cells and incorporation of the intact carotenoid or retinyl ester products into chylomicrons secreted into lymph (Faulks and Southon, 2005. This process is highly influenced by food matrix type (Ornelas-Paz et al., 2008a). Differences in bioavailability and bioconversion in vitamin A for one carotenoid from several foods are caused in part by the food matrix effect (West and Castenmiller, 1998).

Mango (Mangifera indica L.) is a very popular carotenoid-rich fruit in many countries. The yelloworange colored flesh of this fruit is carotenoids-rich however; the carotenoids content in mango is cultivar dependent (Ornelas-Paz et al., 2007). BC content in Ataulfo mango is considerably higher than that of other mango cultivars world-wide (Ornelas-Paz et al., 2008b). This mango cultivar is one of the most important in Mexico in terms of production and consumption. The high availability of Ataulfo mango and its elevated $\mathrm{BC}$ content suggest that this mango cultivar may play an important role on human nutrition and health. Existing data on BC bioavailability from mango fruit and its subsequent bioconversion to vitamin A are scarce and contradictory. The vitamin A value of mango fruit was considered as high, considering only its provitamin A carotenoids content and assuming some factors of bioconversion (Pott et al., 2003). The liver retinol accumulation in rats fed with dried mango suggests a moderate bioavailability of BC from this fruit (Yuyama et al., 1991). In contrast, supplementing with retinyl palmitate and fresh mango was insufficient to correct the vitamin A deficiency of Senegalesse children (Carlier et al., 1992). Recent studies using the in vitro digestion/Caco-2 cell model suggest a low bioavailability of BC from fresh Ataulfo mango (Ornelas-Paz et al., 2008a). At date, the relative bioconversion of provitamin A carotenoids from fresh mango fruit in vitamin A has not been assessed nor compared with that of other BC sources. The objective of this study was determinate the efficiency of bioconversion of $\mathrm{BC}$ from Ataulfo mango and carrots.

\section{MATERIALS AND METHODS}

Animals, foods, reagents and solvents: Seven-week old male albino Wistar rats (45) were obtained from the Instituto de Neurobiologia de la Universidad Nacional Autonoma de Mexico. Fresh ripe mangoes (cv. Ataulfo), carrots (cv. Bangor), soybean oil, corn starch, cellulose for rodent diet, sucrose and casein were bought in the local market in Queretaro, Mexico. $\beta$ Carotene, $\beta$-apo- 8 '-carotenal and $\beta$-carotene were obtained from Sigma-Aldrich (St. Louis, MO, USA). Other reagents and solvents were obtained from J.T. Baker (Mallinckrodt-Baker Inc., Mexico), Merck KGaA (Darmstadt, DE) or Sigma-Aldrich (St. Louis, MO, USA), unless stated otherwise.

Experimental design: The design of study was based on rat vitamin A liver depletion and repletion method as described by Zakaria-Rungkat et al. (2000). Rats were housed separately in hanging numbered cages and maintained on a 12:00 h light-dark cycle with free access to water. The average ambient temperature and relative humidity were $22.7 \pm 0.3^{\circ} \mathrm{C}$ and $53.0 \pm 2.0 \%$, respectively. All rats were put on a standard commercial NIH-31:18-4413110-75-52 diet (Zeigler Bros., Inc., Gardnerds, PA, USA) for 1 week adaptation period. After that, a portion (25-35 $\mathrm{g} \mathrm{rat}^{-1}$ ) of Vitamin $A$ and carotenoids Deficient Diet (VADD) was delivered daily to the animals during 12 weeks depletion period. At weeks $0,4,8$ and 12, five rats were sacrificed to monitor their liver retinol. After the depletion period, the rats were fed with VADD and one of five test foods for 2 weeks repletion period. The test foods were 122.1-132.1 $\mu \mathrm{g}$ of synthetic BC dissolved in $120 \mu \mathrm{L}$ soybean oil $(\mathrm{BC}+\mathrm{O})$, Ataulfo Mango cubes + $120 \mu \mathrm{L}$ soybean oil $(\mathrm{M}+\mathrm{O})$, Ataulfo Mango cubes $(\mathrm{M})$, transverse Carrot slices (C) and $120 \mu \mathrm{L}$ soybean Oil (O). Mango fruit and carrots were daily purchased in the local marked during repletion period. Test foods also were evaluated daily for retinol, BC and Total Carotenoids (TC) contents previously to be delivered to the rats. A sterile insulin syringe equipped with a single-use sterile animal feeding needle $(18 \times 2 \mathrm{~mm})$ (Popper and Sons, Inc., New Hyde Park, NY, USA) was used to deliver the soybean oil, either alone or containing $\mathrm{BC}$. The access to VADD was restricted 
until daily portions of test foods were completely consumed, which occurred within $1.5 \mathrm{~h}$ of the onset of feeding. Excepting O, the test foods provided an identical daily low amount of BC (122.1-132.1 $\left.\mu \mathrm{g} \mathrm{rat}^{-1}\right)$. After repletion, the rats were sacrificed to measure their liver retinol. The bioconversion efficiency of $\mathrm{BC}$ and $\mathrm{TC}$ from test foods in vitamin $\mathrm{A}$ were determined by the retinol accumulation factors $\left(\mathrm{RAF}_{\mathrm{BC}}\right.$ and $\left.\mathrm{RAF}_{\mathrm{TC}}\right)$, which were calculated by dividing the total intake of $\mathrm{BC}\left(\mathrm{I}_{\mathrm{BC}}\right)$ or $\mathrm{TC}\left(\mathrm{I}_{\mathrm{TC}}\right)$ during the repletion period by the corresponding Liver Retinol Accumulation (LRA). Body weight was measured weekly throughout the experiment. Daily consumption of VADD was determined weekly during the depletion period. Consumption of VADD and test foods was evaluated daily during the repletion period.

Elaboration of the Vitamin $A$ and carotenoids Deficient Diet (VADD): VADD was prepared weekly according to the formulation described by Pasatiempo et al. (1989). Briefly, $1 \mathrm{Kg}$ of VADD was composed of casein (226 g), corn starch (375 g), sucrose powder (202.2 g), soybean oil (107.5 g), cellulose $(52.7 \mathrm{~g})$, L-methionine $(4 \mathrm{~g})$, dibasic calcium phosphate (18.4 g), magnesium oxide (883.2 $\mathrm{mg})$, potassium citrate (monohydrate, $8.1 \mathrm{~g}$ ), potassium sulfate (1.9 g), sodium chloride (2.7 g), chromium potassium sulfate $(20.3 \mathrm{mg})$, cupric carbonate $(11.1 \mathrm{mg})$, potassium iodate $(0.4 \mathrm{mg})$, ferric citrate $(220.8 \mathrm{mg})$, manganous carbonate $(128.8 \mathrm{mg})$, sodium selenite $(0.4 \mathrm{mg})$, zinc carbonate $(58.9 \mathrm{mg})$, vitamin $\mathrm{D}_{3}(2.6 \mathrm{mg})$, vitamin $\mathrm{E}$ acetate $(105 \mathrm{mg})$, menadione sodium bisulfite $(0.9 \mathrm{mg})$, $1 \%$ biotin $(0.2 \mathrm{mg}), 1 \%$ cyanocobalamin $(0.1 \mathrm{mg})$, folic acid $(2.1 \mathrm{mg})$, niacin $(31.5 \mathrm{mg})$, calcium pantothenate (16.8 $\mathrm{mg})$, pyridoxine hydrochloride $(7.4 \mathrm{mg})$, riboflavin $(6.3 \mathrm{mg})$ and thiamin hydrochloride $(6.3 \mathrm{mg})$.

Analysis of $\boldsymbol{\beta}$-Carotene (BC) and Total Carotenoids (TC) in test foods: Carotenoids from fresh carrots $(1 \mathrm{~g})$, mangoes ( $2 \mathrm{~g}$ ) and VADD ( $\mathrm{g}$ ) were extracted according to the method described by Ornelas-Paz et al. (2008b). Food samples were homogenized in the presence of calcium carbonate $(0.2 \mathrm{~g})$ and methanol $(15 \mathrm{~mL})$. The homogenate was filtered through a filter paper, adding methanol until retained solids became colorless. The methanolic extract was mixed with $50 \mathrm{~mL}$ of a mixture of hexane: acetone $(1: 1, \mathrm{v} / \mathrm{v})$ containing $0.1 \%$ of BHT. After vigorous stirring, $40 \mathrm{~mL}$ of $10 \%$ sodium sulfate was added for phase separation. The upper layer was separated, washed several times with water and evaporated in a rotavapor (Buchi Labortechnik AG, Flawil, Switzerland) at $35^{\circ} \mathrm{C}$. The residue was dissolved in 2-propanol $(5 \mathrm{~mL})$ and filtered throughout a polyethylene membrane of $0.45 \mu \mathrm{m}$ pore size (Millipore Corp., Bedford, MA, USA). Soybean oil samples (120 $\mu \mathrm{L})$, either alone or containing BC, were diluted with 2 $\mathrm{mL}$ of 2-propanol: hexane (1.5:98.5, v/v) and filtered, as described above. Filtered carotenoid extracts were automatically injected $(25 \mu \mathrm{L})$ into an HP 1100 series HPLC system (Hewlett-Packard, GmbH, DE) equipped with an online degasser, quaternary pump, column thermostat $\left(25^{\circ} \mathrm{C}\right)$ and diode array detector. A YMC Carotenoid $\mathrm{C}_{30}$ reversed-phase column $(4.6 \times 150 \mathrm{~mm}, 3$ $\mu \mathrm{m})$ was used (YMC Inc., Wilmington, NC, USA). BC was monitored at $452 \mathrm{~nm}$. The mobile phase was composed by methanol (A) and tert-butyl methyl ether (B). A linear gradient from 72 to $64.4 \% \mathrm{~A}$ in $12 \mathrm{~min}$ was used at a flow rate of $1 \mathrm{~mL} \mathrm{~min}^{-1}$. Pure $\mathrm{BC}$ and $\alpha$ Carotene (AC) was used for identification and quantification purposes. $\beta$-Apo-8'-carotenal was used as internal standard. Aliquots $(200 \mu \mathrm{L})$ of filtered carotenoids extracts were also diluted with 2-propanol $(1800 \mu \mathrm{L})$ and TC content was determined by a Beckman DU-65 spectrophotometer (Beckman Instruments Inc., Palo Alto, CA, USA) at $452 \mathrm{~nm}$ using synthetic BC as external standard.

Rats sacrifice and liver collection: Rats were sacrificed by carbon dioxide asphyxiation, according to the Mexican Official Norm (NOM-062-ZOO-1999). The liver was immediately excised, washed with saline, blotted on paper towels to remove excess blood and saline, weighed and stored $\left(-80^{\circ} \mathrm{C}\right)$ until retinol analysis, which was performed one day later.

Liver retinol analysis: Each liver was homogenized to puree. Samples $(1 \mathrm{~g})$ of pureed livers were immediately homogenized in deionized water $(10 \mathrm{~mL})$. Aliquots $(0.3 \mathrm{~mL})$ of the obtained mixture were mixed with $25 \%$ sodium ascorbate $(0.5 \mathrm{~mL})$, water $(0.7 \mathrm{~mL})$ and ethanol $(2 \mathrm{~mL})$ and heated at $70^{\circ} \mathrm{C}$ for $5 \mathrm{~min}$. The mixture was saponified with $10 \mathrm{M} \mathrm{KOH}(1 \mathrm{~mL})$ for $30 \mathrm{~min}$ at $70^{\circ} \mathrm{C}$ and the retinol was extracted by washing the saponified sample with hexane $(4 \mathrm{~mL})$ four times. Hexane extracts were pooled, evaporated, dissolved in methanol $(2 \mathrm{~mL})$, filtered through a polyethylene membrane of $0.45 \mu \mathrm{m}$ pore size and automatically injected $(25 \mu \mathrm{L})$ into the HPLC system described above. The HPLC system was fitted to a Symmetry $\mathrm{C}_{18}$ reversed-phase column $(4.6 \times 150 \mathrm{~mm}, 3.5 \mu \mathrm{m})$ (Waters, Milford, MA, USA). The column was kept at $30^{\circ} \mathrm{C}$. Retinol was monitored at $325 \mathrm{~nm}$. A mixture of acetonitrile: dichloromethane: methanol: 1-octanol (78.2:13:8.7:0.1, v/v) was used as mobile phase (isocratic system) at a flow rate of $1 \mathrm{~mL} \mathrm{~min}^{-1}$. The identification and quantification of 
retinol in liver samples was carried out by calibration curves constructed using pure retinol as external standard.

Statistical analysis: Data were analyzed in a completely randomized-design. Statistical significance of the difference was determined using ANOVA followed by Tukey-Kramer post hoc test taking 0.05 as the significance limit. Results were expressed as the mean of several measurements \pm standard errors. Data analysis was performed using JMP Statistical Software (SAS Institute Inc., Cary, NC, USA).

\section{RESULTS}

Food consumption and body weight of rats: Daily consumption of VADD changed irregularly throughout the depletion period (Fig. 1), but decreased continuously in all groups during repletion (data not shown). Total consumption of VADD in all experimental groups was similar during the repletion period (Table 1). In spite of variations in VADD consumption, the average body weight of the animals increased continuously during the depletion period (Fig. 1). Body weight at the beginning of the repletion period was identical in all experimental groups, varying from 542.1 to $542.7 \mathrm{~g} \mathrm{rat}^{-1}$ and showed only slight changes during the rest of such period (data not shown). Final body and liver weights of the animals are shown in Table 1. The test foods given to the animals to replete their hepatic retinol were completely consumed. The total amount of test foods consumed during the repletion period is shown in Table 1 .

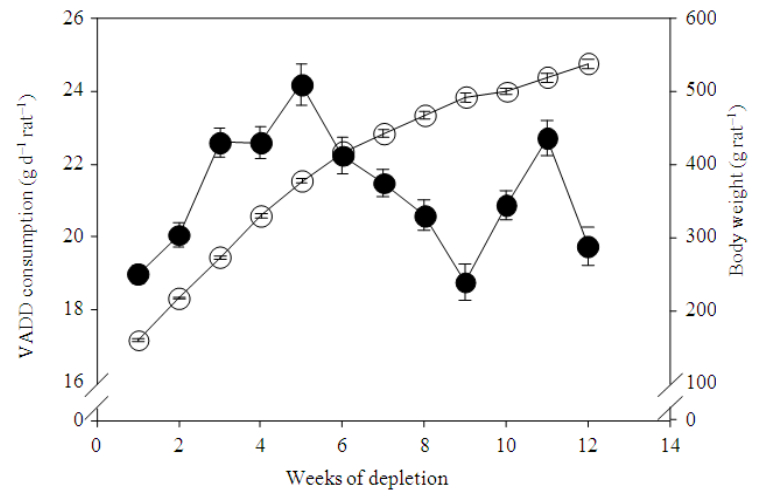

Fig. 1: Daily consumption of VADD $(\bullet)$ and body weight ( 0 ) during the depletion period. Values represent the mean \pm the standard error (vertical slim bars). $\mathrm{N}=40-25$
Vitamin A and carotenoids contents in the foods consumed by the rats: Carotenoids were not detected in soybean oil and VADD but VADD contained some retinol $\left(0.9 \pm 0.1 \mathrm{mg} \mathrm{Kg}^{-1}\right)$. TC content was higher in carrots $\left(112.3 \pm 0.0-213.3 \pm 0.2 \mathrm{mg} \mathrm{Kg}^{-1}\right)$ than in mango fruit (40.4 $\left.\pm 0.1-77.7 \pm 0.2 \mathrm{mg} \mathrm{Kg}^{-1}\right)$. BC was the major carotenoid in all tested carotenoid-rich foods however, $\mathrm{AC}$ was also important in carrots (Fig. 2). AC content in carrots varied from $28.5 \pm 0.1$ to $60.8 \pm 0.8 \mathrm{mg} \mathrm{Kg}^{-1}$. The concentration of $\mathrm{BC}$ in $\mathrm{BC}+\mathrm{O}$ varied slightly dayto-day $\left(1017.2 \pm 23.1-1101.1 \pm 7.6 \mathrm{mgL}^{-1}\right)$ but the volume delivered to the rats was always constant $(120 \mu \mathrm{L})$. The portions of mango and carrots delivered to the rats contained the same amount of BC that $120 \mu \mathrm{L}$ of $\mathrm{BC}+\mathrm{O}$ $(122.1 \pm 2.8-132.2 \pm 0.9 \mu \mathrm{g})$. The daily portions of mango delivered to the rats were larger than those of carrots since $\mathrm{BC}$ content was higher in carrots $\left(87.8 \pm 0.4-164.4 \pm 0.1 \mathrm{mg} \mathrm{Kg}{ }^{-1}\right)$ than in mangoes (17.4 $\left.\pm 0.0-41.2 \pm 0.1 \mathrm{mg} \mathrm{Kg}^{-1}\right)$.

Carotenoids consumption and liver retinol accumulation: The liver retinol was high $(4.2 \pm 0.2 \mathrm{mg}$ liver ${ }^{-1}$ ) at the beginning of the depletion period however, it was reduced $87.5 \%$ during such period (Fig. 3). Hair loss was the main sign of vitamin A deficiency. Test foods provided $\mathrm{BC}$ alone $(\mathrm{BC}+\mathrm{O})$ or mixed with other carotenoids $(\mathrm{M}+\mathrm{O}, \mathrm{M}$ and $\mathrm{C})$. The $\mathrm{I}_{\mathrm{BC}}$ during the repletion period was similar in the groups fed with carotenoids-rich foods, in contrast to $\mathrm{I}_{\mathrm{TC}}$ (Table 2). In spite of similarities in $\mathrm{I}_{\mathrm{BC}}$, LRA varied widely among experimental groups (Table 2). $\mathrm{BC}+\mathrm{O}$ consumption caused the highest LRA.

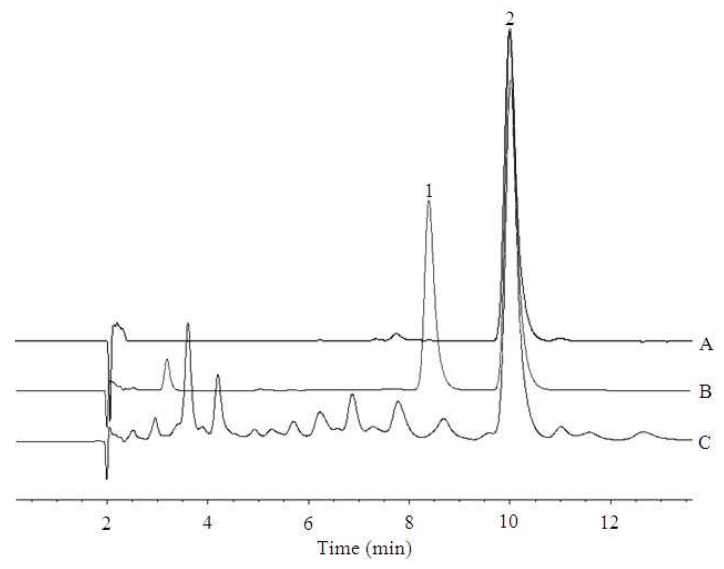

Fig. 2: Typical chromatographic profiles of carotenoids (at $452 \mathrm{~nm}$ ) of the oily solution of BC (A) carrots (B) and Ataulfo mango (C). Peaks 1 and 2 were identified as all-trans- $\beta$-carotene (BC) and all-trans- $\alpha$-carotene (AC), respectively. Peaks not numbered were not studied 
Am. J. Agri. \& Biol. Sci., 5 (3): 301-308, 2010

Table 1: Final body and liver weights and total amount of consumed foods (VADD and test foods) during repletion period

\begin{tabular}{llllc}
\hline Group $^{\dagger}$ & Final body weight $(\mathrm{g})$ & Final liver weight $(\mathrm{g})$ & Consumed VADD $(\mathrm{g})$ & Consumed test food $(\mathrm{g})$ \\
\hline $\mathrm{BC}+\mathrm{O}$ & $544.2 \pm 15.3^{\mathrm{a}}$ & $21.3 \pm 1^{\mathrm{a}}$ & $237.4 \pm 7.7^{\mathrm{a}}$ & $1680.0 \pm 0^{\ddagger}$ \\
$\mathrm{M}+\mathrm{O}$ & $546.1 \pm 15.3^{\mathrm{a}}$ & $20.2 \pm 1^{\mathrm{a}}$ & $214.1 \pm 12.4^{\mathrm{a}}$ & $57.3 \pm 0.1^{\mathrm{a}}$ \\
$\mathrm{M}$ & $552.7 \pm 20.8^{\mathrm{a}}$ & $22.7 \pm 1^{\mathrm{a}}$ & $256.6 \pm 20.7^{\mathrm{a}}$ & $57.0 \pm 0.4^{\mathrm{a}}$ \\
$\mathrm{C}$ & $533.4 \pm 15.3^{\mathrm{a}}$ & $21.7 \pm 1^{\mathrm{a}}$ & $265.7 \pm 7.3^{\mathrm{a}}$ & $15.4 \pm 0^{\mathrm{b}}$ \\
$\mathrm{O}$ & $547.0 \pm 12.5^{\mathrm{a}}$ & $18.8 \pm 1.3^{\mathrm{a}}$ & $267.0 \pm 11.9^{\mathrm{a}}$ & $1680.0 \pm 0^{\ddagger}$ \\
\hline
\end{tabular}

: Vitamin A depleted rats were fed with VADD along with $\beta$-carotene dissolved in $120 \mu \mathrm{L}$ soybean oil (BC $+\mathrm{O}$ ), Ataulfo mango $+120 \mu \mathrm{L}$ soybean oil $(\mathrm{M}+\mathrm{O})$, Ataulfo Mango cubes (M), transverse Carrot slices (C), or $120 \mu \mathrm{L}$ soybean Oil (O) for two weeks. ${ }^{\ddagger}$ : In $\mu \mathrm{L}$. Data represent the mean $(\mathrm{N}=5) \pm$ standard error. Values within the same column with different superscript letters were statistically different $(\mathrm{p}<0.05)$

Table 2: $\mathrm{I}_{\mathrm{BC}}, \mathrm{I}_{\mathrm{TC}}$ and, LRA during repletion period and the corresponding retinol accumulation factors $\left(\mathrm{RAF}_{\mathrm{BC}}, \mathrm{RAF}_{\mathrm{TC}}\right)$

\begin{tabular}{llllll}
\hline Group & $\mathrm{I}_{\mathrm{BC}}(\mathrm{mg})$ & $\mathrm{I}_{\mathrm{TC}}(\mathrm{mg})$ & $\mathrm{LRA}(\mathrm{mg} /$ liver $)$ & $\mathrm{RAF}_{\mathrm{BC}}$ & $\mathrm{RAF}_{\mathrm{TC}}$ \\
\hline $\mathrm{BC}+\mathrm{O}$ & $1.8 \pm 0.0^{\mathrm{a}}$ & $1.8 \pm 0.0^{\mathrm{a}}$ & $1.5 \pm 0.2^{\mathrm{a}}$ & $1.2 \pm 0.1^{\mathrm{a}}$ & $1.2 \pm 0.1^{\mathrm{a}}$ \\
$\mathrm{M}+\mathrm{O}$ & $1.8 \pm 0.0^{\mathrm{a}}$ & $3.4 \pm 0.0^{\mathrm{b}}$ & $1.4 \pm 0.1^{\mathrm{b}}$ & $1.3 \pm 0.1^{\mathrm{a}}$ & $2.5 \pm 0.1^{\mathrm{b}}$ \\
$\mathrm{M}$ & $1.8 \pm 0.0^{\mathrm{a}}$ & $3.4 \pm 0.0^{\mathrm{b}}$ & $1.1 \pm 0.1^{\mathrm{b}}$ & $1.6 \pm 0.1^{\mathrm{a}}$ & $3.1 \pm 0.2^{\mathrm{b}}$ \\
$\mathrm{C}$ & $1.8 \pm 0.0^{\mathrm{a}}$ & $2.3 \pm 0.0^{\mathrm{c}}$ & $0.8 \pm 0.1^{\mathrm{c}}$ & $2.4 \pm 0.3^{\mathrm{b}}$ & $3.1 \pm 0.3^{\mathrm{b}}$ \\
$\mathrm{O}$ & $\mathrm{ND}^{\ddagger}$ & $\mathrm{ND}^{\ddagger}$ & $0.3 \pm 0.1^{\mathrm{d}}$ & $\mathrm{ND}^{\ddagger}$ & $\mathrm{ND}^{\ddagger}$ \\
\hline
\end{tabular}

: Vitamin A depleted rats were fed with VADD along with $\beta$-carotene dissolved in $120 \mu \mathrm{L}$ soybean oil (BC $+\mathrm{O}$ ), Ataulfo mango $+120 \mu \mathrm{L}$ soybean oil $(\mathrm{M}+\mathrm{O})$, Ataulfo Mango cubes $(\mathrm{M})$, transverse Carrot slices $(\mathrm{C})$, or $120 \mu \mathrm{L}$ soybean Oil $(\mathrm{O})$ for two weeks. ${ }^{*}$ : ND $=$ Not detected. Data represent the mean value of five samples analyzed in duplicate $(\mathrm{N}=10) \pm$ standard error. Values within the same column with different superscript letters were statistically different $(\mathrm{p}<0.05)$

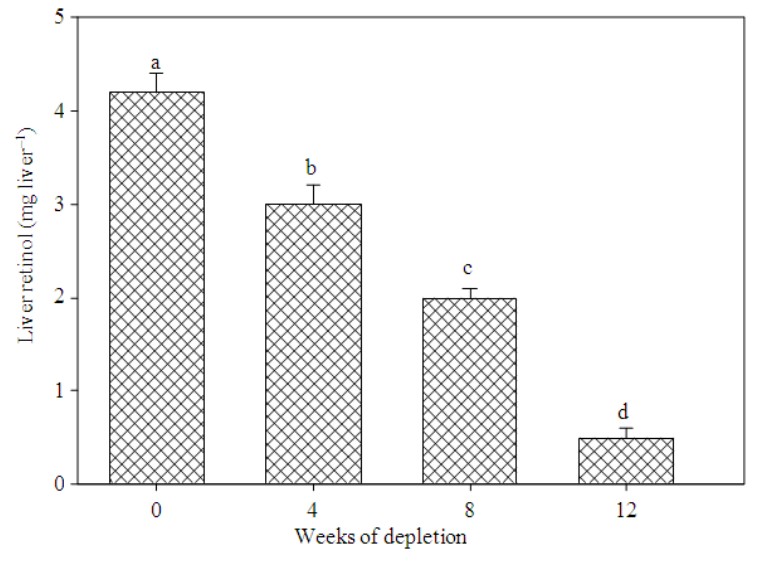

Fig. 3: Liver retinol during the depletion period. Values represent the mean of five livers analyzed in duplicate $(\mathrm{N}=10) \pm$ standard error (vertical slim bars). Bars with different superscript letters were statistically different $(\mathrm{p}<0.05)$

$\mathrm{M}+\mathrm{O}$ consumption caused a higher but not significant LRA than M. Rats fed with $C$ showed the lowest LRA in spite of that $\mathrm{C}$ provided a significant additional total amount of $\mathrm{AC}$ of $0.6 \pm 0.0 \mathrm{mg}$ during repletion. Liver retinol content in rats fed with $\mathrm{O}$ diminished during repletion, representing such content at the end of the experiment $5.9 \%$ of the initial liver retinol. The bioavailability of $\mathrm{BC}$ and the vitamin $\mathrm{A}$ value of total carotenoids from test foods, expressed as $\mathrm{RAF}_{\mathrm{BC}}$ or $\mathrm{RAF}_{\mathrm{TC}}$, were ranked as follows: $\mathrm{BC}+\mathrm{O}>\mathrm{M}$ $+\mathrm{O}>\mathrm{M}>\mathrm{C}$ (Table 2).

\section{DISCUSSION}

Since $90 \%$ of the vitamin A reserve is located in the rat liver and such reserve can be readily depleted or repleted by restricting or providing provitamin A carotenoids, the relative efficiency of bioconversion in vitamin A and bioavailability of BC and other provitamin A carotenoids from foods can be easily assessed by monitoring the changes in vitamin A in livers from rats consuming test foods (Zakaria-Rungkat et al., 2000). This strategy was used in this study to compare the bioconversion efficiency of carotenoids from fresh Ataulfo mangoes and carrots in vitamin A.

VADD consumption varied during the depletion period (Fig. 1). A virtually identical VADD consumption behavior has been reported during depletion of Charles Foster rats (Nambiar and Seshadri, 2001). In that study and in our study the maximum VADD consumption was observed at week 5 of the depletion period. A clear descendent behavior in VADD consumption was observed during the repletion period of the present study. Ingestion of test foods and the vitamin A deficient status in rats were probably responsible of such reduction. Vitamin A deficiency in rats causes atrophying of the circumvillate papilla, leading to loss of taste and diminishing food consumption (Nambiar and Seshadri, 2001). Nonetheless, neither vitamin A deficiency nor reduced food consumption affected negatively body weight gain of the animals throughout the experiment. Gardner and Ross (1993) demonstrated that a severe vitamin A deficiency does not affect growing in rats. In general, the changes in body weight observed herein were 
similar to those reported in other similar studies (Yuyama et al., 1991; Zakaria-Rungkat et al., 2000).

$\mathrm{BC}$ was the major carotenoid in the carotenoidsrich foods tested. Ornelas-Paz et al. (2008a; 2008b) demonstrated by HPLC-MS that BC is the main provitamin A carotenoid in Ataulfo mango. Similar results have been reported for other mango cultivars (Mercadante and Rodriguez-Amaya, 1998). The maximum BC content in Ataulfo mangoes $\left(41.2 \pm 0.1 \mathrm{mg} \mathrm{Kg}^{-1}\right)$ found in this study was similar to that of Gedong mangoes, but higher than those previously reported in Manalagi, Indramayn, Harum Manis, Golek, Haden, Tommy Atkins, Mangga and Keitt mangoes (Mercadante and Rodriguez-Amaya, 1998; Hulshof et al., 1997). Violaxanthin (all-trans and 9-cis) is the other important carotenoid in Ataulfo mango pulp (Ornelas-Paz et al., 2008a; 2008b) however; violaxanthin has not provitamin A activity. In contrast to mangos, two provitamin A carotenoids (BC and $\mathrm{AC}$ ) almost represented the TC content in carrots. The content of BC and AC in carrots in this study was similar to that reported in the literature (Niizu and Rodriguez-Amaya, 2005).

The initial liver retinol was considerably high. Similar values have been reported in Wistar rats (Ameny et al., 2002). This initial high liver retinol prevented reaching the levels of vitamin A depletion reported by others (Zakaria-Rungkat et al., 2000; Graebner et al., 2004) in despite of that vitamin A content in consumed VADD was remarkably low. After depletion, liver retinol increased significantly as a consequence of consuming carotenoids-rich foods for two weeks. BC from test foods was highly absorbed and stored as retinol in rat livers. This high efficiency absorption and bioconversion could be a consequence of the small $\mathrm{BC}$ dose delivered to the rats from foods. In contrast to previous works (Zakaria-Rungkat et al., 2000; Graebner et al., 2004), in the present study the test foods were not mixed with a basal diet, increasing the bioavailability of $\mathrm{BC}$ and other provitamin $\mathrm{A}$ carotenoids from foods. Basal diet generally includes fiber (Graebner et al., 2004), which reduces carotenoids absorption (Horvitz et al., 2004).

In rats fed with $\mathrm{BC}+\mathrm{O}$, each microgram of liver retinol was originated by consuming $1.2 \mu \mathrm{g}$ of $\mathrm{BC}$ $\left(\mathrm{RAF}_{\mathrm{BC}}=1.2\right)$. This bioconversion efficiency was higher than those previously reported $\left(\mathrm{RAF}_{\mathrm{BC}}=2-3.3\right)$ in rats fed with oily solutions of $\mathrm{BC}$ (Tanumihardjo, 2002; Brubacher and Weiser, 1985). This might be a consequence of the very small BC dose daily delivered to the rats from $\mathrm{BC}+\mathrm{O}$. Furusho et al. (2000) demonstrated that the retinol equivalence of dietary carotenoids in rats was higher with a small amount of carotenoids than with a large amount. The requirement of BC (as oily solution) in humans to form $1 \mu \mathrm{g}$ retinol is also low $(2.4 \mu \mathrm{g})$ when $\mathrm{BC}$ is administered at low doses (Van Lieshout et al., 2001), in spite of that BC absorption and bioconversion to vitamin $\mathrm{A}$ is lower in humans than in rats (West and Castenmiller, 1998). The $\mathrm{RAF}_{\mathrm{BC}}$ was statistically similar in $\mathrm{BC}+\mathrm{O}, \mathrm{M}+\mathrm{O}$ and $M$ groups, suggesting that the negative effect of the food matrix of mango on carotenoid bioavailability was considerably low. Similarly, Sweeney and Marsh (1974) did not find differences in LRA in Wistar rats fed with carrots or an oily solution of $\mathrm{BC}$, both providing daily a lower BC dose $\left(60 \mu \mathrm{g}\right.$ rat $\left.^{-1}\right)$ than that administered in the present study (122.1-132.1 $\left.\mathrm{g} \mathrm{gat}^{-1}\right)$. The bioavailability of low doses of lycopene in humans is also similar when lycopene is delivered as ketchup or as an oily solution (Rao and Shen, 2002). So far, only one study has been published on the bioconversion of mango BC in vitamin A in rats. That study (Yuyama et al., 1991) demonstrated that depleted rats fed with dried Brazilian mangoes accumulated $40 \%$ less retinol than those fed preformed vitamin $\mathrm{A}$, suggesting a moderate bioavailability of mango BC. However, such results must be cautiously considered because drying of the fruit can induce structural changes and carotenoids losses (Pott et al., 2003), altering the potential bioavailability of mango carotenoids. The present study demonstrated for the first time that the relative bioavailability of $\mathrm{BC}$ from fresh mangoes in rats is high when it is ingested at low doses. The co-consumption of mango and soybean oil $(\mathrm{M}+\mathrm{O})$ increased slightly LRA as compared with consumption of $\mathrm{M}$, although statistically differences were not found. The positive effect of dietary fat on carotenoids bioavailability has been demonstrated. In vivo, increased intake of fat increases secretion of pancreatic lipases and bile (Ge et al., 1996), promoting the formation of mixed micelles and the micellarization of carotenoids, two basic steps necessary for carotenoids absorption (Faulks and Southon, 2005). Since BC was the unique provitamin A carotenoid in mango fruits, the $\mathrm{RAF}_{\mathrm{TC}}$ lacks of relevance for rats fed with such food.

$\mathrm{RAF}$ in the group fed with $\mathrm{C}$ was lower than that previously reported $\left(\mathrm{RAF}_{\mathrm{BC}}=12, \mathrm{RAF}_{\mathrm{TC}}=22\right)$ by Zakaria-Rungkat et al. (2000). The low BC amount in $\mathrm{C}$ consumed by rats in the present study was probably the consequence of this, as reported previously (Furusho et al., 2000). Unexpectedly, rats fed with C showed lower LRA that those fed with $M$ in spite of that $\mathrm{C}$ contained $\mathrm{AC}$, a carotenoid that possesses 50$54 \%$ of the provitamin A activity of BC (Pott et al., 2003). These results demonstrate that provitamin A carotenoids from $\mathrm{M}$ are more bioavailable than those of C. This could be explained in terms of differences between mango and carrots regarding to firmness, fiber content, how carotenoids are stored in chromoplasts and 
absorptive interactions among carotenoids. Ripe mango fruit is softer than carrots and therefore mechanical and enzymatic disruption of mango tissue during digestion could be more efficient than that of carrots, leading to an increased carotenoids releasing from food. Disruption of cell walls from foods is closely related to the carotenoids bioavailability (West and Castenmiller, 1998). Fiber content is also higher in carrots than in mangoes (Munoz et al., 1996). Several studies have demonstrated that the ingestion of fibers decreases carotenoids bioavailability. Horvitz et al. (2004) demonstrated that carrot fibers reduce carotenoids bioavailability in humans. Pasquier et al. (1996) showed that several dietary fibers increased the viscosity of reconstituted duodenal medium and affected fat emulsification and lipolysis, two indispensable steps for carotenoid micellarization and absorption (Faulks and Southon, 2005). Some fibers can also decrease pancreatic lipase activity and bind bile acids (Pasquier et al., 1996), reducing the formation of micelles and the subsequent carotenoid micellarization. On the other hand, BC is stored in mango chloroplasts as an oily solution and as big solid crystals in carrots. Crystalline carotenoids are less bioavailable than lipid-dissolved carotenoids (Horvitz et al., 2004) and therefore a lower LRA can be expected in rats fed with carrots. Finally, the low LRA found in rats fed with $\mathrm{C}$ might be explained by absorptive interactions among $\mathrm{AC}$ and $\mathrm{BC}$ from $\mathrm{C}$. Furusho et al. (2000) demonstrated that LRA in Wistar rats was significantly reduced when an $\mathrm{BC}$ amount was replaced by a mixture of $\mathrm{AC}$ and $\mathrm{BC}$, both containing the same amount of $\mathrm{BC}$, suggesting that each one of these carotenoids mutually inhibits the utilization of the other. The proportion of $\mathrm{AC}$ to $\mathrm{BC}$ in the mixture used in that study simulated that of carrots. $\mathrm{RAF}_{\mathrm{TC}}$ in rats fed with $\mathrm{C}$ considers the bioconversion of $\mathrm{BC}$ and $\mathrm{AC}$ and suggests that the provitamin $\mathrm{A}$ value of $\mathrm{C}$ is lower than that of mango $(M+O$ and $M)$.

\section{CONCLUSION}

Ataulfo mango was more effective than carrots in improving vitamin A status in deficient rats. These results also confirm that low doses of dietary carotenoids are efficiently absorbed, bioconverted to vitamin A and stored as retinol. Further studies are needed to test the potential of mango in improving the vitamin A status in humans routinely ingesting the fruit.

\section{ACKNOWLEDGMENT}

The researchers express their sincere thanks to Lissette A. Aburto-Juarez for caring the animals and to Sandra Garcia for providing some VADD components.

\section{REFERENCES}

Ameny, M.A., J. Raila, E. Walzel and F.J. Schweigert, 2002. Effect of iron and/or vitamin A and iron status of rats after a dietary deficiency of both components. J. Trace Elem. Med. Biol., 16: $175-178$. DOI: $10.1016 /$ S0946$672 X(02) 80021-9$

Bertram, J.S. and A.L. Vine, 2005. Cancer prevention by retinoids and carotenoids: Independent action on a common target. Biochem. Biophys. Acta, 1740: 170-178. DOI: 10.1016/j.bbadis.2005.01.003

Brubacher, G.B. and H. Weiser, 1985. The vitamin A activity of $\beta$-carotene. Int. J. Vit. Nutr. Res., 55: 5-15. PMID: 3997397

Carlier, C., M. Etchepare, J.F. Ceccon, M.S. Mourey and O. Amedee-Manesme, 1992. Efficacy of massive oral doses of retinyl palmitate and mango (Mangifera indica L.) consumption to correct an existing vitamin A deficiency in Senegalese children. Br. J. Nutr., 68: 529-540. DOI: 10.1079/BJN19920110

Faulks, R.M. and S. Southon, 2005. Challenges to understanding and measuring carotenoid bioavailability. Biochim. Biophys. Acta, 1740: 95-100. DOI: 10.1016/j.bbadis.2004.11.012

Furusho, T., E. Kataoka, T. Yasuhara, M. Wada and S. Masushige, 2000. Retinol equivalence of carotenoids can be evaluated by hepatic vitamin A content. Int. J. Vit. Nutr. Res., 70: 43-47. DOI: 10.1024/0300-9831.70.2.43

Gardner, E.M. and A.C. Ross, 1993. Dietary vitamin A restriction produces marginal vitamin A status in young rats. J. Nutr., 123: 1435-1443. PMID: 8336215

Ge, K., D. Liu, K. Chen, L. Nie and S. Yao, 1996. Determination of lipase activity in porcine pancreas and clinical analysis of lipase in human serum with surface acoustic wave enzyme sensor system. Fresenius. J. Anal. Chem., 354: 118-121. DOI: $10.1007 / \mathrm{s} 002169600020$

Graebner, I.T., E.M.A. Siquiera, S.F. Arruda and E.M.T. Souza, 2004. Carotenoids from native Brazilian dark-green vegetables are bioavailable: A study in rats. Nutr. Res., 24: 671-679. DOI: 10.1016/j.nutres.2003.10.012

Horvitz, M. A., P.W. Simon and S.A. Tanumihardjo, 2004. Lycopene and $\beta$-carotene are bioavailable from lycopene 'red' carrots in humans. Eur. J. Clin. Nutr., 58: 803-811. DOI: 10.1038/sj.ejcn. 1601880

Hulshof, P.J.M., C. Xu, P. van de Bovenkamp, Muhilal and C.E. West, 1997. Application of a validated method for the determination of provitamin a carotenoids in Indonesian foods of different maturity and origin. J. Agric. Food Chem., 45: 1174-1179. DOI: 10.1021/jf9603137 
Mercadante, A.Z. and D.B. Rodriguez-Amaya, 1998. Effects of ripening, cultivar differences and processing on the carotenoid composition of mango. J. Agric. Food Chem., 46: 128-130. DOI: 10.1021/jf9702860

Munoz, C.M., V.A. Chavez, A.J.A. Roldan, S.J.A. Ledesma and M.E. Mendoza et al., 1996. Tables of the Nutritional Value of Foods (in Spanish). Pax, ISBN: 970-10-3278-0, pp: 80.

Nambiar, V.S. and S. Seshadri, 2001. Bioavailability trials of $\beta$-carotene from fresh and dehydrated drumstick leaves (Moringa oleifera) in a rat model. Plant Foods Hum. Nutr., 56: 83-95. DOI: 10.1023/A:1008132503972

Niizu, P.Y. and D.B. Rodriguez-Amaya, 2005. New data on the carotenoid composition of raw salad vegetables. J. Food Compost. Anal., 18: 739-749. DOI: 10.1016/j.jfca.2004.09.001

Ornelas-Paz, J.J., E.M. Yahia and A.A. Gardea-Bejar, 2007. Identification and quantification of xanthophyll esters, carotenes and tocopherols in the fruit of seven Mexican mango cultivars by liquid chromatography-APcI ${ }^{+}$-time of flight mass spectrometry. J. Agric. Food Chem., 55: 6628-6635. PMID: 17625873

Ornelas-Paz, J.J., E.M. Yahia and A. A. Gardea-Bejar, 2008a. Changes in external and internal color during postharvest ripening of 'Manila' and 'Ataulfo' mango fruit and relationship with carotenoid content determined by liquid chromatography-APcI ${ }^{+}$-timeof-flight mass spectrometry. Postharvest Biol. Technol., 50: 145-152. DOI: 10.1016/j.postharvbio.2008.05.001

Ornelas-Paz, J.J., M.L. Failla, E.M. Yahia and A.A. Gardea-Bejar, 2008b. Impact of the stage of ripening and dietary fat on in vitro bioaccessibility of $\beta$-carotene in 'Ataulfo' mango. J. Agric. Food Chem., 56: 1511-1516. DOI: 10.1021/jf072751r

Pasatiempo, A.M.G., T.A. Bowman, C.E. Taylor and A.C. Ross, 1989. Vitamin A depletion and repletion: Effects on antibody response to the capsular polysaccharide of Streptococcus pneumoniae, type III (SSS-III). Am. J. Clin. Nutr., 49: 501-510. PMID: 2784283

Pasquier, B., M. Armand, F. Guillon, C. Castelain and P. Borel et al., 1996. Viscous soluble dietary fibers alter emulsification and lipolysis of triacylglycerols in duodenal medium in vitro. J. Nutr. Biochem., 7: 293-302. DOI: 10.1016/0955-2863(96)00030-7

Pott, I., M. Marx, S. Neidhart, W. Muhlbauer and R. Carle, 2003. Quantitative determination of $\beta$ carotene stereoisomers in fresh, dried and solardried mango (Mangifera indica L.). J. Agric. Food Chem., 51: 4527-4531. DOI: 10.1021/jf034084h
Rao, A.V. and H. Shen, 2002. Effect of low dose lycopene intake on lycopene bioavailability and oxidative stress. Nutr. Res., 22: 1125-1131. DOI: 10.1016/S0271-5317(02)00430-X

Rivera, A.J. and J. Sepulveda, 2003. Conclusions from the Mexican National Nutrition Survey 1999: translating results into nutrition policy. Salud Publica Mex., 45: S565-S575. PMID: 14746051

Sampaio, A.R.D., C.E.A. Chagas, T.P. Ong and F.S. Moreno, 2007. Vitamin A and $\beta$-carotene inhibitory effect during 1,2-dimethylhydrazine induce hepatocarcinogenesis potentiated by 5azacitidine. Food Chem. Toxicol., 45: 563-567. DOI: 10.1016/j.fct.2006.10.001

Sweeney, J.P. and A. Marsh, 1974. Liver storage of vitamin A by rats fed carrots in various forms. J. Nutr., 104: 1115-1120. PMID: 4853023

Tanumihardjo, S.A., 2002. Factors influencing the conversion of carotenoids to retinol: Bioavailability to bioconversion to bioefficacy. Int. J. Vit. Nutr. Res., 72: 40-45. DOI: 10.1024/0300-9831.72.1.40

Van Lieshout, M., C.E. West, Muhilal, D. Permaesih and Y. Wang et al., 2001. Bioefficacy of $\beta$ carotene dissolved in oil studied in children in Indonesia. Am. J. Clin. Nutr., 73: 949-958. PMID: 11333850

Van Vliet, T., W.H.P. Schereurs and H. van den Berg, 1995. Intestinal $\beta$-carotene absorption and cleavage in men: Response of $\beta$-carotene and retinyl esters in the triglyceride-rich lipoprotein fraction after a single oral dose of $\beta$-carotene. Am. J. Clin. Nutr., 62: 110-116. PMID: 7598052

West, C.E. and J.J.M. Castenmiller, 1998. Quantification of the "SLAMENGHI" factor for carotenoid bioavailability and bioconversion. Int. J. Vit. Nutr. Res., 68: 371-377. PMID: 9857264

Yahia, E.M. and J.J. Ornelas-Paz, 2010. Chemistry, Stability and Biological Actions of Carotenoids. In: Fruit and Vegetable Phytochemicals: Chemistry, Nutritional Value and Stability, De la Rosa, L.A., E. Alvarez-Parrilla and G.A. Gonzalez-Aguilar (Eds.). Wiley-Blackwell, ISBN: 13: 978-0-81380320-3/2010, pp: 177-222.

Yuyama, L.K.O., R.M.D. Favaro, K. Yuyama and H. Vannucchi, 1991. Bioavailability of vitamin a from peach palm (Bactris gaspiaes $\mathrm{H}$. B. K) and from mango (Mangifera indica L.) in rats. Nutr. Res., 11: 1167-1175. DOI: 10.1016/S02715317(05)80694-3

Zakaria-Rungkat, F., M. Djaelani, R. Setiana and E. Nurrochmah, 2000. Carotenoid bioavailability of vegetables and carbohydrate containing food measured by retinol accumulation in rat livers. J. Food. Compost. Anal., 13: 297-310. DOI: 10.1006/jfca.2000.0871 